\title{
INTERVIEW
}

For reprint orders, please contact: reprints@futuremedicine.com

\section{Easing the strain of movement disorders: from translational and clinical science to rehabilitation} strategies

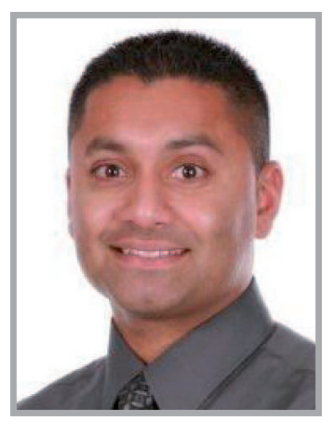

Quincy J Almeida*: Quincy Almeida is the Director of the Sun Life Financial Movement Disorders Research and Rehabilitation Centre at Wilfrid Laurier University (ON, Canada), one the world's leading authorities on movement science and rehabilitation in Parkinson's disease (PD). His research has been featured in the Toronto Star, the Globe \& Mail, on CBC and CTV national news as well as features in Maclean's magazine. He has been funded by the Canadian Institutes of Health Research, Natural Sciences and Engineering Research Council of Canada and by a multimillion dollar grant from the Canada Foundation for Innovation, and his innovative research on PD has won several awards, including the Franklin Henry Young Scientist Award for motor control in Canada, and the Parkinson's Society of Canada Young Investigator's Award. More recently, he received the Polanyi Prize for Physiology and Medicine, the Queen Elizabeth's II Diamond Jubilee medal in January 2013, and in June 2013 Almeida gave a keynote when he was honored with a North American Award, the Early Career Distinguished Scholar Award from the North American Society for the Psychology of Sport and Physical Activity organization at a conference in New Orleans (LA, USA). Almeida has spoken about his novel approach to understanding PD across the world, including in France, Italy, Brazil, Ireland, Norway, Australia and The Netherlands.

Q Could you tell our readers a little about your career to date \& how you came to your current role?

I am the founder and current Director of the Sun Life Financial Movement Disorders Research and Rehabilitation Centre at Wilfrid Laurier University (ON, Canada). Having completed my training in urban centers that have large, reputable and research-based hospitals (in Toronto, [ON, Canada], London [ON, Canada] and Hamilton [ON, Canada]), I realized that the suburban region I now live in suffered from a severe shortage of clinical services and research facilities to help support individuals with Parkinson's disease (PD) and other movement disorders. With funding from the Canada Foundation for Innovation, Sun Life Financial and many private donors, we were able to convert an abandoned public school into a stateof-the-art research facility for movement disorders.

Each classroom is now an assessment facility for walking, balance, speech, arm/hand movements and cognitive function, while the school gym has been renovated into a PD rehabilitation studio. Even the principal's office has been converted into a clinical neuroassessment facility for movement disorders.

Q How do you split your time between your different roles? How important is it for you to spend time carrying out research as well as working in the community?

As a professor in the Faculty of Science at Wilfrid Laurier University, my role as an educator involves not only teaching at the

*Movement Disorders Research \& Rehabilitation Centre, Wilfrid Laurier University, 75 University Avenue West, Waterloo, N2L 3C5, ON, Canada; qalmeida@wlu.ca

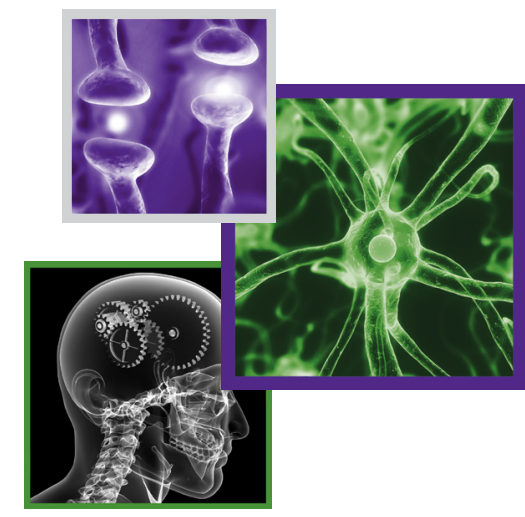

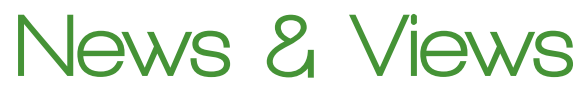

News

Journal Watch

Ask the Experts

Interview

Conference Scene 
graduate and undergraduate level, but also, in a very literal sense, educating those who have just received a movement disorder diagnosis. All too often, patients are given a diagnosis and a prescription and sent out the door so fast that their heads are still spinning. As we enroll participants in our research, we help to educate them about what they may expect from their illness. Amazingly, as people participate in very carefully crafted research experiments, they start to learn more about their abilities and disabilities, thus making research a very powerful tool for educating individuals about their disease. As our research center grows, we continue to search for ways we can assist in more rural areas of Ontario (Canada), and hundreds of patients come from across the globe to stay actively involved in our research. In some cases, participants access new and innovative rehabilitation programs, while others gain access to internationally created inventions that aim to help relieve the symptoms of movement disorders, without the need for pharmacological management.

Q What is the role of the Sun Life Movement Disorders Research \& Rehabilitation Centre?

Our research center is considered to be a 'onestop' shop for any movement disorders patient; from speech, to walking and cardiovascular assessment, our facility serves hundreds of patients, mainly from Ontario, but also from across North America and the world. We have also created the largest virtual reality laboratory for PD patients in North America.

Q What is your current research focusing on? We have three main streams of research at our facility. First, we aim to understand the basic science of the underlying mechanisms of the motor symptoms in PD (and other basal ganglia movement disorders); for example, if the slowness of movement that is typically seen in PD was really the result of slow cognitive processing or slow eye movements, then this would be important to know, since treating these eye movements or cognitive problems might result in improvement to the general bradykinesia seen in PD.

Second, we attempt to take our basic science findings and translate them into potential therapeutic interventions that might help to reduce disease symptoms. Thus, we have played a major role in identifying scientifically validated rehabilitation strategies for individuals with PD, as well as evaluating other alternatives, such as physioacoustic vibration therapies. As part of the International Consensus Committee on Clinical Exercise Prescription, some of these recommendations will be made globally available [1-3].

Finally, as mentioned above, as our international reputation grows, inventions from across the world continue to pour in, with requests from both scientists and inventors to evaluate the effectiveness of their devices. Inventions have included laser and optic flow devices to improve gait, facilitatory insoles to enhance balance and haptic devices to enhance coordination between the upper limbs.

\section{Q What is known about the neurocognitive \& neuromotor mechanisms underlying movements in the context of neurodegenerative disorders?}

Our research has demonstrated that many factors, such as visual processing speed, slowness of eye movements, and proprioceptive and cognitive deficits, can all have a profound impact on the typical symptoms that are seen in PD and many other basal ganglia disorders. Making these advances will revolutionize how we treat and understand PD and many other movement disorders.

\section{Q How successfully has movement science been translated into exercise advice for PD patients?}

We have been very fortunate to develop a program known as PD Sensory Attention Focused Exercise (SAFEx), which targets some of the underlying sensory and attention mechanisms that contribute to the symptoms of PD. This program has repeatedly been able to demonstrate a reduction of PD symptoms, with studies published in peer-reviewed, international journals including Neurodegerative Disease Management $[4,5]$. We continue to evaluate many other strategies that are exercise based, in the hope of finding other alternatives.

\section{Q What types of exercise do you recommend for patients with PD?}

As demonstrated in the some of our publications in Neurodegerative Disease Management and Movement Disorders, it is certainly true that not all exercises are created equal when it comes to dealing with neurodegenerative conditions, such as PD [3-5]. Some strategies, such as stretching and walking, have little-to-no benefit 
at all for PD-specific symptoms. However, it is important to recognize that $\mathrm{PD}$ also generally leads to inactivity. Therefore, some physical activity to combat osteoporotic processes and cardiovascular decline are better than doing nothing at all.

\section{Q To what extent can movement} interventions improve quality of life?

Movement interventions, including exercise and other occupational-type strategies (e.g., cueing), can have a dramatic impact on quality of life [6]. It is also important to realize that staying active, especially when in group settings, can have a tremendous social impact as well.

\section{Q What has been your greatest academic achievement to date?}

I have been very fortunate to be recognized for the research accomplishments of our group. This June, I gave a keynote when I received the Early Career Distinguished Scholar Award from the North American Society for the Psychology of Sport and Physical Activity. To be recognized at this level is always tremendously humbling, but to be honest, the greatest achievement is always when I have a patient who comes in and reports something that they can now do that they have not been able to for the last several years, for example, 'I no longer need my wheelchair', 'I'm cooking again!' or 'My balance is good enough that I just painted the side of my house'. No reward could be greater than seeing someone's face when they tell you something like this.

\section{Q What are you excited about working on in} the coming year?

We have some very exciting new research making use of virtual reality environments. This will allow us to measure and understand how much of a role anxiety plays in influencing movement symptoms. For example, while we know that anxiety (e.g., getting into an argument or stressful situation) certainly increases Parkinsonian tremor, we are not quite sure whether shuffling or freezing of gait might be associated with feeling like you are about to fall off the edge of a cliff. Virtual reality will allow us to solve this question, without putting the patients at any risk.

This year we also look forward to being able to make PD SAFEx publicly accessible to anyone who wants access to this rehabilitation strategy.

Q How do you foresee the field progressing in the next 5 years? What major challenges need to be faced?

The biggest challenge, as always, will be research funding. It is always difficult to have to turn someone away, or cancel a study that has the potential to make a major breakthrough, because of a lack of funding. We all know that it is a difficult financial time globally, and, unfortunately, research will also feel the brunt of this.

\section{Disclaimer}

The opinions expressed in this interview are those of the interviewee and do not necessarily reflect the views of Future Medicine Ltd.

\section{Financial \& competing interests disclosure}

QJ Almeida has no relevant affiliations or financial involvement with any organization or entity with a financial interest in or financial conflict with the subject matter or materials discussed in the manuscript. This includes employment, consultancies, honoraria, stock ownership or options, expert testimony, grants or patents received or pending, or royalties.

No writing assistance was utilized in the production of this manuscript.

\section{References}

1 Jones LW, Pituskin E, Battaglini CL. Exercise training in oncology: systematic review and clinical practice recommendations. Health Fitness J. Canada 5(1), 47-63 (2012).

2 Pang MY, Charlesworth SA, Lau RW, Chung RC. Using aerobic exercise to improve health outcomes and quality of life in stroke: evidence-based exercise prescription recommendations. Cerebrovasc. Dis. 35(1), 7-22 (2013).

3 Sage MD, Almeida QJ, Johnston RE. Comparison of exercise strategies for motor symptom improvement in Parkinson's disease. Neurodegen. Dis. Manage. 1(5), 387-395 (2011).

4

Sage MD, Almeida QJ. A positive influence of vision on motor symptoms during sensory attention focused exercise for Parkinson's disease. Mov. Disord. 25(1), 64-69 (2010).

5 Sage MD, Almeida QJ. Symptom and gait changes after sensory attention focused exercise vs aerobic training in Parkinson's disease. Mov. Disord. 24(8), 1132-1138 (2009).

6 Johnson AM, Almeida QJ. The impact of exercise rehabilitation and physical activity on the management of Parkinson's disease. Geriatrics Aging 10(5), 318-321 (2007). 